\title{
New record of Caenis nigropuctatula Malzacher, 2015 (Ephemeroptera: Caenidae) from Southern India
}

\section{Pandiarajan SRINIVASAN', Thambiratnam SIVARUBAN¹, Sivaruban BARATHY², Rajasekaran ISACK ${ }^{1}$}

Cite this article as:

Srinivasan, P., Sivaruban, T., Barathy, S., Isack, R. (2021). New record of Caenis nigropuctatula Malzacher, 2015 (Ephemeroptera: Caenidae) from Southern India. Aquatic Research, 4(3), 299-303. https://doi.org/10.3153/AR21024

${ }^{1}$ The American College, PG \& Research department of Zoology, Madurai625002, India

${ }^{2}$ Fatima College, Department of Zoology, Madurai-625018, India

\section{ORCID IDs of the author(s):}

P.S. 0000-0001-8118-3256

T.S. 0000-0001-8997-9355

S.B. 0000-0002-9464-6464

R.I. 0000-0002-9952-4335

Submitted: 04.04 .2021

Revision requested: 26.04 .2021

Last revision received: 03.05 .2021

Accepted: 09.05.2021

Published online: 16.05 .2021

Correspondence:

Thambiratnam SIVARUBAN

E-mail: sivaruban270@gmail.com

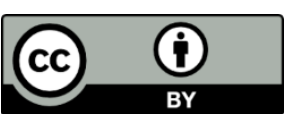

(C) 2021 The Author(s)

Available online at

http://aquatres.scientificwebjournals.com

\begin{abstract}
Caenis nigropuctatula Malzacher, 2015, a new mayfly record of the fauna of Indian Ephemeroptera, is recorded from the Vaigai River, Tamil Nadu, India. It is known before from Thailand, Java, and Sumatra. The distribution map of $C$. nigropuctatula is given.
\end{abstract}

Keywords: Caenis nigropuctatula, India, Mayfly, New record 


\section{Introduction}

The following are the described species of Caenis known from India: C. picea Kimmins, 1947; C. incurva Malzacher, 2015; C. piscina Kimmins, 1947; C. srinagari Traver, 1939; C. maratha Malzacher, 2015; C. kimminsis Ali, 1967 and $C$. americani Srinivasan, Sivaruban, Barathy, Malzacher \& Isack, 2021. Of the seven species, three are known from Southern India (C. maratha, C. kimminsis, and C. americani); however, the current status of $C$. kimminsis is vague as Ali (1967) described this species as a superficial one which lacks informative drawings (Staniczek et al., 2020). We determine a new record of Caenis nigropunctatula Malzacher, 2015 based on comparing the samples that we have collected with the existing collections. Differential diagnosis of $\mathrm{C}$. $n i$ gropunctatula is confirmed based on the literature of Malzacher, 2015. From this new record, the species number of Caenis in India has expanded to eight. With poor available data of Caenis species, the Biomonitoring status remains insufficient, so more work to be carried out on family Caenidae in India and other Oriental regions.

\section{Material and Methods}

The specimens were collected from the Vaigai River, Madurai, Tamil Nadu, India (Figure 1). 7 larvae were collected using a $\mathrm{D}$ net and all of them were subsequently reared into imago in the laboratory and were collected and preserved in $80 \%$ ethanol. The imagos of $C$. nigropunctatula were easily reared from mature nymphs having dark wing pads and they can become imagos within a week in the rearing tank at $32^{\circ} \mathrm{C}$ without any aeration and food. Adult characteristics of $C$. $n i$ gropunctatula were studied using Magnus MSZ binocular stereo microscope and photographs were acquired using Canon EOS 1500D. Specimens studied under Scanning electron microscope were first dehydrated using ethanol and dried by critical point drying and examined with an EVO-18 scanning electron microscope at $10 \mathrm{k}$. Digital SEM photographs were made and edited with Adobe Photoshop 7.0. Terminologies were followed based on Malzacher (1991) for male genital sclerites and Kluge (1994) for thoracic structures. The distributional map of Caenis nigropuctatula was done with the help of the software SimpleMappr (Shorthouse 2010). The collected specimens are deposited in the American College Museum (AMC), Madurai, and Tamil Nadu.

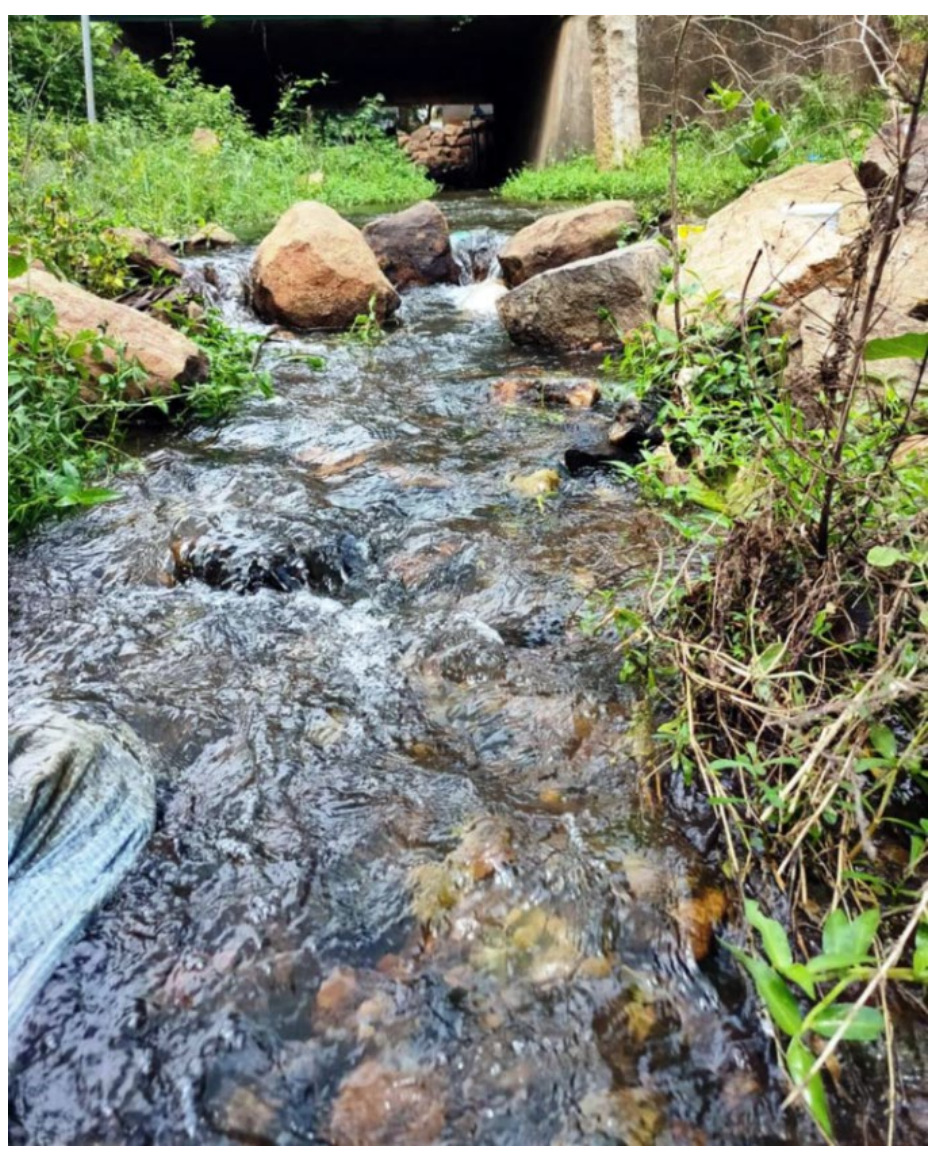

Figure 1. Habitat of Caenis nigropunctatula Malzacher, 2015

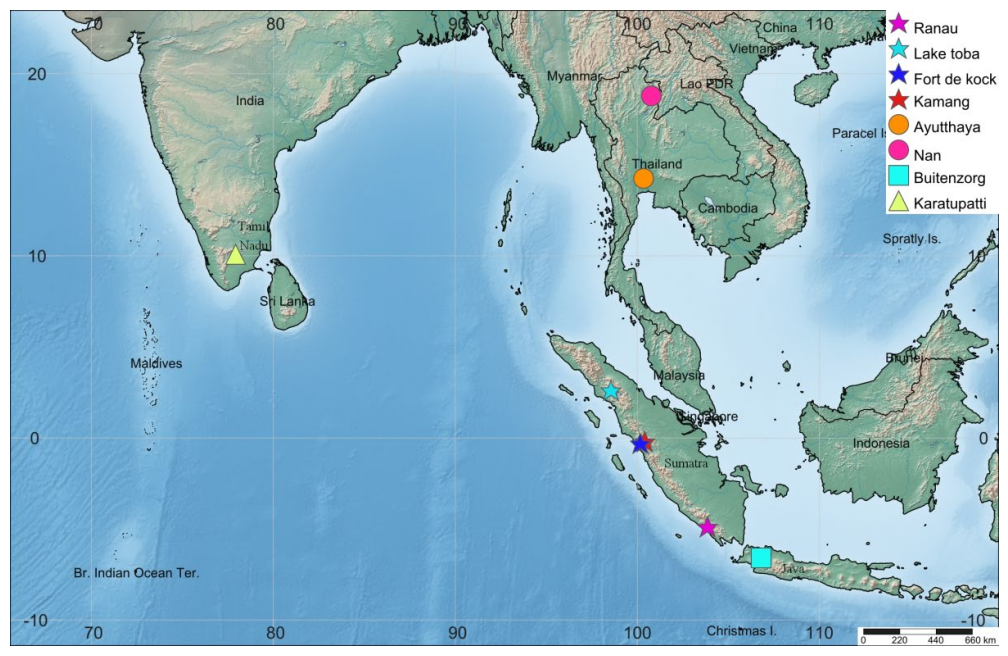

Figure 2. Distributional map of Caenis nigropunctatula Malzacher, 2015 


\section{Results and Discussion}

Caenis nigropuctatula Malzacher, 2015 (Figure 3)

Caenis nigropuctatula Malzacher, 2015: 28, Figures 1a-1, 2a-e, 41, 8-15.

\section{Non-Type Material Examined}

2 male imagos (AMC/ZN/199), 3 female imagos (AMC/ZN/200), South India, Tamil Nadu, Madurai, Vaigai River, $10^{\circ} 08324^{\prime} \mathrm{N} \& 7^{\circ} 93220^{\prime} \mathrm{E} ; 192$ m; 3/X/2020, Pandiarajan Srinivasan \& Rajasekaran Isack.

\section{Description}

Caenis nigropunctatula is known earlier from Thailand, Java and Sumatra (Malzacher, 2015). This is the first record that it is known from India and the extension of this species goes over 1000 kilometers (Figure 2). C. nigropunctatula also shows a wide range of intraspecific variations in leg ratios, however, the genitalia remains similar in all individuals of various populations (Malzacher, 2015). The Indian population of $C$. nigropunctatula shows the comparative kind of attributes of Thailand population as the apical dilation of tarsomere remains small. The characters of the Indian population are as follows: size of male imago- $3.5 \mathrm{~mm}$ (Figure 3A); size of female imago- $4.3 \mathrm{~mm}$ (Figure $3 \mathrm{~B}$ ); wing length- $2.1 \mathrm{~mm}$; cerci length- $5.4 \mathrm{~mm}$; length of foreleg- $2.1 \mathrm{~mm}$; head length ratios: c:a- 2.34; a:b- 1.07; ratio of forefemur: foretibia- 0.58 ; ratio of foretibia: foretarsus- 1.27; ratio of foreleg: hindleg1.47; ratio of segments of fore tarsus $1 \mathrm{st}: 2 \mathrm{nd}: 3 \mathrm{rd}: 4$ th $: 5$ th $=1: 4: 2.2: 2.1: 1.3$; ratio of body length $:$ length of cercus : length of terminal filament $=1: 2.8: 3.8$.

Caenis nigropunctatula can be distinguished from all other Caenis species in male imago (Malzacher, 2015) by strong prosternal ridges and forms an isosceles triangle (Figure 3C); tarsomeres 2-4 of fore tarsus apically broadened; broadenings with small strong spines, not tongue-shaped (Figures 3E \& $3 \mathrm{~F}$ ); proportion of forefemur : foretibia $=$ more than 0.46 ; proportion of foreleg : hindleg = less than 1.90; Penis broad, with rounded lobes of moderate length (Figure $3 \mathrm{G}$ ); forceps marginally narrowed to the tip, with a short spine pretty much bent medially (Figure $3 \mathrm{H}$ ).
The lone contrast of character we noted from the Indian population is the fore margin between lateral and frontal ocelli slightly bowed in the head of the adult imagos (Figure 3D) but in other populations, it looks straight (Malzacher, 2015). Therefore, further analysis is needed in other parts of India and the rest of the Oriental region to know the exact status of Caenis nigropunctatula and its disparities among various populations.

Of the eight known species of Caenis from India, C. piscina, $C$. srinagari, and $C$. kimminsis lacks important diagnostic characters, as both $C$. piscina and $C$. srinagari are distinguished based on their color pattern only whereas C. kimminsis lacks the novel diagnostic features of larvae. So, these three species should be redescribed soon based on the fresh material from their particular localities. The key to male for C. picea, C. incurva, C. maratha, and C. nigropunctatula was given by Malzacher (2015), Malzacher \& Sangpradub (2020). So, based on modern diagnostic characters about half of the species of Caenis described from India needs quick redescription soon to sort out problems in the taxonomy of Caenidae in India.

\section{Distribution}

Thailand, India (new record), Indonesia (Sumatra and Java).

\section{Conclusion}

The present study confirms the presence of Caenis nigropunctatula in Tamil Nadu, Southern India. The distribution range of $C$. nigropunctatula remains unknown as the earlier findings in Thailand and Indonesia lack ecological characteristics of C. nigropunctatula, so it is unable to predict the distribution range of $C$. nigropunctatula at the present scenario. The findings of the present study reveal the taxonomy and morphology of this particular species and help to know more about the phylogenetic relationship of mayflies in India. 


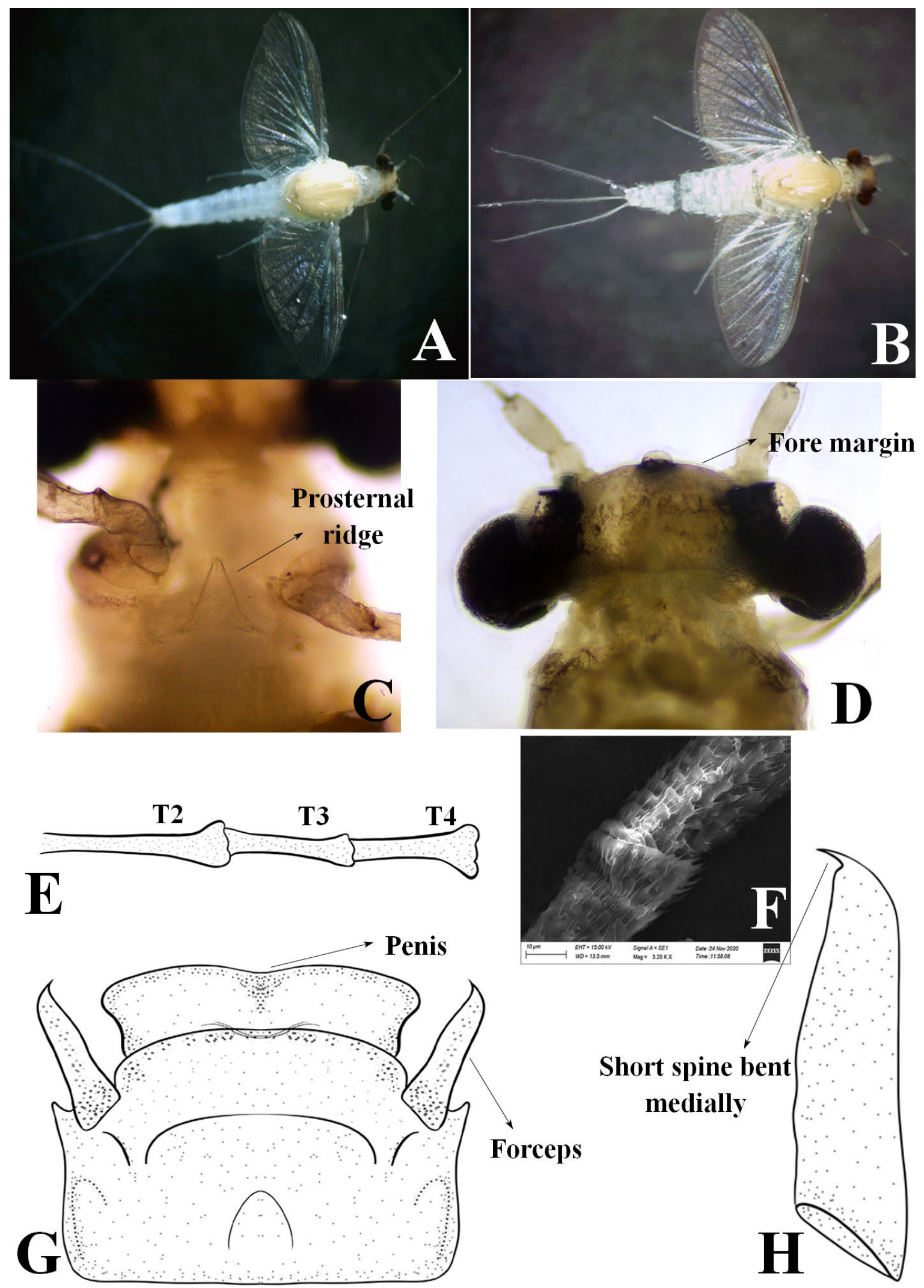

Figure 3. Caenis nigropunctatula Malzacher, 2015 (A-H). A- male imago; B- female imago; C- prosternal ridge; D- head of male imago; E- structure of fore tarsomere; F- SEM view of tarsomere 3; G- male genitalia; H- forceps 


\section{Compliance with Ethical Standard}

Conflict of interests: The authors declare that for this article they have no actual, potential or perceived conflict of interests.

Ethics committee approval: All authors declare that this study does not include any experiments with human or animal subjects.

Funding disclosure: -

Acknowledgments: We thank Dr. Peter Malzacher for his assistance in finding this new record in India.

Disclosure: -

\section{References}

Ali, S.R. (1967). The mayfly nymphs (Order: Ephemeroptera) of Rawalpindi district. Pakistan Journal of Science, 19, 73-86.

Kimmins, D.E. (1947). New species of Indian Ephemeroptera. Proceedings of the Royal Society of London (B), 16, 92100 .

https://doi.org/10.1111/j.1365-3113.1947.tb00865.x

Kluge, N. (1994). Pterothorax structure of mayflies (Ephemeroptera) and its use in systematics. Bulletin de la Société Entomologique de France, 99 (1), 41-61.

Malzacher, P. (1991). Genital-morphological features in the Caenidae. In J. Alba-Tercedor \& A. Sánchez-Ortega (Eds.), Overview and strategies of Ephemeroptera and Plecoptera (p. 73-85). Florida, Gainesville: Sandhill Crane Press.
Malzacher, P. (2015). Revision of the Oriental species of the genus Caenis Stephens (Insecta: Ephemeroptera: Caenidae). Stuttgarter Beiträge zur Naturkunde A, Neue Serie 8, 27-47.

Malzacher, P., Sangpradub, N. (2020). New mayfly species of Caenis and Kalimaenis from Thailand and descriptions of two new genera of the subfamily Caeninae (Ephemeroptera: Caenidae). Integrative Systematics: Stuttgart Contributions to Natural History, 3(1), 1-33.

https://doi.org/10.18476/insy.v03.a1

Staniczek, A.H., Malzacher, P., Bojková, J., Sroka, P., Soldán, T., Namin, J.I., Godunko, R.J. (2020). Caenidae (Insecta: Ephemeroptera) of Iran, with new records and redescription of the nymph of Caenis kopetdagi Kluge, 1985. Aquatic Insects, 41(2), 106-130.

https://doi.org/10.1080/01650424.2020.1735449

Shorthouse, D.P. (2010). SimpleMappr, an online tool to produce publication-quality point maps. https://www.simplemappr.net [accessed 18 Apr. 2021]

Srinivasan, P., Sivaruban, T., Barathy, S., Malzacher, P., Isack, R. (2021). A new charismatic Caenis Stephens, 1835 (Ephemeroptera: Caenidae) from Southern India. Zootaxa, 4926(1), 105-116.

https://doi.org/10.11646/zootaxa.4926.1.7

Traver, J.R. (1939). Himalayan mayflies (Ephemeroptera). Annals and Magazine of Natural History, 11(4), 32-56. https://doi.org/10.1080/00222933908526972 